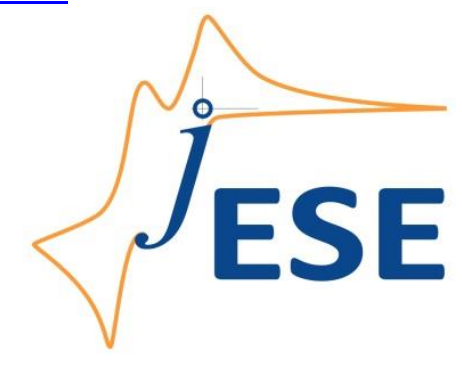

Open Access : : ISSN 1847-9286

www.jESE-online.org

Original scientific paper

\title{
Nickel contamination analysis at cost-effective silver printed paper-based electrodes based on carbon black dimethyl- glyoxime ink as electrode modifier
}

\author{
Keagan Pokpas ${ }^{1}$, Nazeem Jahed $^{1, \bowtie}$, Petrone Bezuidenhout ${ }^{2}$, Suzanne Smith ${ }^{2,3}$, \\ Kevin Land ${ }^{2,3}$ and Emmanuel Iwuoha ${ }^{1}$ \\ ${ }^{1}$ SensorLab, Department of Chemistry, University of the Western Cape, Robert Sobukwe Road, \\ Bellville, 7530, South Africa \\ ${ }^{2}$ Materials Science and Manufacturing, Council for Scientific and Industrial Research (CSIR), Meiring \\ Naude Road, Brummeria, Pretoria 0001, South Africa \\ ${ }^{3}$ Department of Electrical, Electronic, and Computer Engineering, University of Pretoria, Hatfield, \\ 0028 South Africa

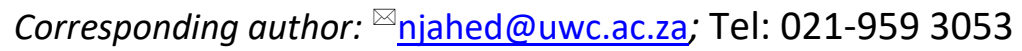

Received: November 14, 2021; Accepted: December 31, 2021; Published: January 14, 2022

\begin{abstract}
Electrochemical detection of metal cations at paper-based sensors has been suggested as an attractive alternative to current spectroscopic and chromatographic detection techniques due to the ease of fabrication, disposable nature, and low cost. Herein, a novel carbon black (CB), dimethylglyoxime (DMG) ink is designed as an electrode modifier in conjunction with 3-electrode inkjet-printed paper substrates for use in the adsorptive stripping voltammetric electroanalysis of nickel cations in water samples. The developed method provides a novel, low-cost, rapid, and portable adsorptive stripping detection approach towards metal analysis in the absence of the commonly used toxic metallic films. The study demonstrated a novel approach to nickel detection at paper-based sensors and builds on previous work in the field of paper-based metal analysis by limiting the use of toxic metal films. The device sensitivity is improved by increasing the active surface area, electron transfer kinetics, and catalytic effects associated with non-conductive dimethylglyoxime films through $C B$ nanoparticles for the first time and confirmed by electroanalysis. The first use of the CB-DMG ink allows for the selective preconcentration of analyte at the electrode surface without the use of toxic Mercury or Bismuth metallic films. Compared to similarly reported paper-based sensors, improved limits of detection (48 $\left.\mu \mathrm{g} \mathrm{L}^{-1}\right)$, selectivity, and intermetallic interferences were achieved. The method was applied to the detection of nickel in water samples well below World Health Organization (WHO) standards.
\end{abstract}

\section{Keywords}


Carbon black; dimethylglyoxime; nickel; stripping voltammetry

\section{Introduction}

Remediation of metal pollution and its quantitative analysis remains a major area of focus for analytical chemists worldwide with considerable funding and time dedicated to novel and innovative means for improving current methods. Heavy metal pollution continues to garner significant attention due to its hazardous effects on the environment and organisms owing to its nonbiodegradable and toxic nature [1]. Current spectroscopic and chromatographic techniques for monitoring this pollution are limited by their high costs, cumbersome equipment, and skilled operation [2]. Therefore, much attention has been placed on low-cost, rapid, and portable means of analysis. Electrochemical detection of metal ions is one such technique that offers highly selective, repeatable, and sensitive quantitative analysis [3]. To date, a range of metal pollutants has been determined by electroanalysis including heavy, platinum group, and transition metals. Nickel determination has been studied following several approaches, however, adsorptive stripping voltammetry remains the most effective technique utilized [4]. The method relies on the reduction of the metallic species from a stable metal-centered coordination complex formed with inorganic chelating agents or biological materials [4,5]. Several metallic films have been suggested to aid in the accumulation of the metal analyte at the electrode surface [6-8], but work has been done to improve the detection capability when a metallic film is not employed.

Carbon nanomaterials have been extensively studied as electrode modifiers in electrochemical sensor applications. Graphene [9,10] carbon nanotubes [11,12], carbon dots [13,14], fullerenes [15], carbon onions, and other nano-sized carbon structures have been effective in improving the sensitivity of sensors owing to their high active surface, large surface-to-volume ratio, improved electron transfer properties, increased stability, and wide active potential window. These nanoscale carbon sensors have been utilized in a diverse array of applications, however, the cost of synthesis, tedious preparation methods, and lack of availability hinder their use. To combat this, carbon black (CB) nanoparticles have been proposed as electrode modifiers for cannabis seed oil, antihypertensive drugs, phenolic compounds, DNA, flavonoids, and metal analysis. Carbon black offers comparable results to other carbon nanostructured sensors[16-23]. It is a commonly available carbon source with elemental carbon arranged in aggregates of fine particles from $3-100 \mathrm{~nm}$. The nanomaterial is often employed as thin film or electrode coating in conjunction with other nanoparticles and active materials. Recently, few studies have proposed the use of CB-based sensors to enhance the sensitivity of electrochemical sensors for stripping voltammetric analysis [24-28]. However, few studies have been conducted for metal analysis. To date, no work has been reported on the use of carbon black in conjunction with chelating agents to form composite materials to improve detection sensitivity and selectivity in adsorptive stripping voltammetric detection of metal ions.

Paper-based sensor use has steadily gained traction as an analytical technique in recent times due to the increased availability, ease of modification, capillary flow, and biodegradable nature [29]. Many standard analytical systems have been adapted to paper-based methods including colorimetric and electrochemical detection. The excellent sorption behaviour of the paper-based devices makes it an attractive option for these analysis systems creating lateral flow and origami devices particularly for use in resource-limited settings on the African continent where access to costly instrumentation and skilled laboratories is lacking. Due to this access to proper medical care is delayed causing severe illnesses. Hydrophobic paper substrates have also been studied by 
several laboratories to replace costlier carbon, metallic and ceramic substrates through coating via printing techniques. While screen-printing is the simplest and most employed method, inkjet printing has been suggested as a suitable alternative [30-32]. Owing to these benefits, electrochemical sensors [33-38] and energy devices [39-43] have recently been reported based on inkjet printing. Inkjet-printed paper electrodes have previously been studied by our research group where a graphene, gold nanoparticle composite was studied in the presence of a mercury film for Nickel detection. To date, a number of works have reported the use of paper-based sensors for stripping voltammetric analysis of metal ions. Here, screen-printed electrodes, paper disks, and microfluidic devices have been studied. However, only the work by Pokpas et al. has shown the applicability of paper-based devices to be used in adsorptive stripping voltammetry for metal ions. This study demonstrated the first use of nanostructured carbon materials for use in adsorptive detection mechanisms for metal analysis. The low sensitivity of paper-based sensors remains the biggest drawback of the technique to date $[7,44]$. As a result, metallic films like mercury are still readily employed. Further work to improve the sensitivity for detection towards metal cations is required before commercial use of these is implemented and particularly to eliminate the use of commonly used amalgam and alloy formation. In addition, no work has been reported to utilize carbon black inks over costlier nanomaterials to enhance the sensitivity of paper-based electrodes.

In this work, a disposable inkjet-printed paper electrode is fabricated for the rapid, cost-effective, and portable detection of Nickel, metal cations in water samples as an electrochemical sensor. The detection sensitivity and selectivity of the low-cost silver printed paper electrodes were improved through modification with carbon black dimethylglyoxime (CB-DMG) paste as electrode modifier in the absence of a metallic film. The CB-DMG allows for effective preconcentration of the electrode surface with Nickel cations in the form of Ni-DMG complexes while maintaining excellent electron transfer properties required for electrochemical detection. The study builds on previous work by our research group for use of inkjet-printed paper-electrodes in adsorptive stripping voltammetric detection of metal ions. Furthermore, the study showcases an attractive alternative to the use of toxic mercury films previously studied. The developed, point-of-care sensor was applied to the detection of metal ions in tap water samples below the World health organization (WHO) limits of detection of $0.1 \mathrm{mg} \mathrm{L}^{-1}$ and demonstrates for the first time a carbon black ink combined with a chelating agent, dimethylglyoxime as electrode modifier.

\section{Experimental}

\section{Apparatus}

A Fujifilm Dimatix DMP-3281 materials deposition printer was employed for all inkjet printing following DesignCAD templates onto Penguin photo paper. All electrochemical voltammetric experiments were performed with a Metrohm Autolab PGSTAT101 instrument, in combination with the Nova 1.11 software, and controlled by a personal computer. All electrochemical experiments were performed in one compartment $20 \mathrm{~mL}$ voltammetric cells at room temperature unless stated otherwise.

\section{Chemicals and reagents}

All chemicals used in the study were of analytical reagent grade. Ultra-pure distilled water (Millipore) was used to prepare all solutions. Harima NPS-JL-nano-silver ink, for low-temperature curing (Harima Chemicals Group) and carbon conductive paste for screen printing (Gwent Group), was used without modification. Nafion perfluorinated resin solution $5 \mathrm{wt} \%$ in lower aliphatic 
alcohols and water, 2,3-Butanedione-dioxime (Dimethylglyoxime) and Nickel(II) standard stock solutions ( $1 \mathrm{~g} \mathrm{~L}^{-1}$, atomic absorption standard solution) were obtained from Sigma-Aldrich and diluted as required. Carbon black was purchased from Alfa Aesar. Ammonia/Ammonium Chloride $\left(\mathrm{NH}_{3} / \mathrm{NH}_{4} \mathrm{Cl}\right)$ buffer solution $(0.1 \mathrm{M}, \mathrm{pH} 9.3)$, prepared by mixing appropriate quantities of ammonia $\left(\mathrm{NH}_{3}\right)$ and ammonium chloride $\left(\mathrm{NH}_{4} \mathrm{Cl}\right)$ was used as supporting electrolyte for all studies. A Metrohm $827 \mathrm{pH}$ lab pH meter was calibrated using pH 4 and 7 calibration buffer solutions and then used to verify the $\mathrm{pH}$ of the prepared $\mathrm{NH}_{3} / \mathrm{NH}_{4} \mathrm{Cl}$ buffer solution.

\section{Design and fabrication of carbon-coated AgNP inkjet-printed electrodes}

A similar procedure described in our previous work was utilized for inkjet-printed electrode preparation. Generally, a piezoelectric materials printer was used to carry out all inkjet printing of Harima NPS-JL-nano-silver ink onto hydrophobic photographic paper.

Preparation of nafion, dimethylglyoxime, carbon black, silver printed paper-based electrodes ( $N$ DMG-CB-Ag-PPE)

Appropriate quantities of carbon black $(0.8 \mathrm{~g})$ and dimethylglyoxime $(0.2 \mathrm{~g})$ were mixed in a nafion solution ( $0.2 \mathrm{wt}$. \%, in EtOH) to prepare the nafion-dimethylglyoxime-carbon black (N-DMG-CB) ink. The viscosity of the prepared ink was adjusted using EtOH if needed. A variety of CB: DMG ratios were prepared as needed. Consecutive, $5 \mu \mathrm{L}$ aliquots of as-prepared N-DMG-CB ink were drop-cast and screen printed onto the working electrode to prepare the Nafion/Dimethylglyoxime/Carbon black/Silver Printed Paper Electrodes (N-DMG-CB-Ag-PPEs). N-DMG-CB-Ag-PPEs were dried at $85^{\circ} \mathrm{C}$ for 1 hour.

\section{Procedure for the SW-AdCSV analysis of $\mathrm{Ni}^{2+}$}

The N-DMG-CB-Ag-PPE was used to analyze a $10 \mathrm{~mL}$ sample of $0.1 \mathrm{M}$ ammonia buffer $(\mathrm{pH} 9.4$ ) $\mathrm{Ni}^{2+}$ containing $2 \mathrm{mM}$ DMG and $10 \mathrm{mg} \mathrm{L}^{-1} \mathrm{Hg}^{3+}$ respectively. The electrochemical detection was carried out by cathodic stripping voltammetry between $-0.7 \mathrm{~V}$ and $-1.35 \mathrm{~V}$ with a $120 \mathrm{~s}$ accumulation time at -0.7 V. $f=5 \mathrm{~Hz}$ and Amplitude $=10 \mathrm{mV}$.

\section{Results and discusion}

\section{$\mathrm{Ni}^{2+}$ detection at the CB-DMG-Ag-PPPE}

Silver printed working electrodes have shown low sensitivity towards [ $\left.\mathrm{Ni}\left(\mathrm{dmgH}_{2}\right)\right]$ complex detection and a narrow active potential window, as discussed in previous sections. Carbon inks have been shown to significantly improve the active potential window and have shown a clear affinity towards the desired application. Carbon black ink, formed from the nanoparticle form of carbon was proposed as an ultrasensitive carbon coating material to further improve the electrode sensitivity of inkjet-printed paper-based sensors in the absence of an electroplated metallic film. Figure 1 represents typical square-wave adsorptive cathodic stripping voltammograms (SW-AdCSV) for $300 \mu \mathrm{g} \mathrm{L}^{-1}$ $\mathrm{Ni}^{2+}$ at the carbon black silver printed paper electrode (CB-Ag-PPPE) and carbon black/dimethylglyoxime silver printed paper electrode (CB-DMG-Ag-PPPE) respectively. The CB-Ag-PPPE shows no cathodic stripping peaks in the active potential window between -0.7 and $-1.3 \mathrm{~V}$ in $0.1 \mathrm{M}$ $\mathrm{NH}_{3} / \mathrm{NH}_{4} \mathrm{Cl}$ Buffer (pH 9.4) with deposition potential (- $0.7 \mathrm{~V}$ ), deposition time (120 s), frequency (5 $\mathrm{Hz}$ ), amplitude (0.1 V) and voltage step (0.005 V). In contrast, the CB-DMG-Ag-PPPE shows a sharp, well-resolved stripping peak at $-1.14 \mathrm{~V}$ for $\mathrm{Ni}^{2+}$ reduction from the formed $\left[\mathrm{Ni}\left(\mathrm{dmgH}_{2}\right)\right.$ ] adsorption complex at the electrode surface. Immobilization of the chelating agent at the electrode surface in conjunction with the high active surface area and conductive carbon nanoparticles provides sensitive 
and selective detection of $\mathrm{Ni}^{2+}$ cations. The overall electrolytic reaction may be described in the twostep process below (Equations 1 and 2):

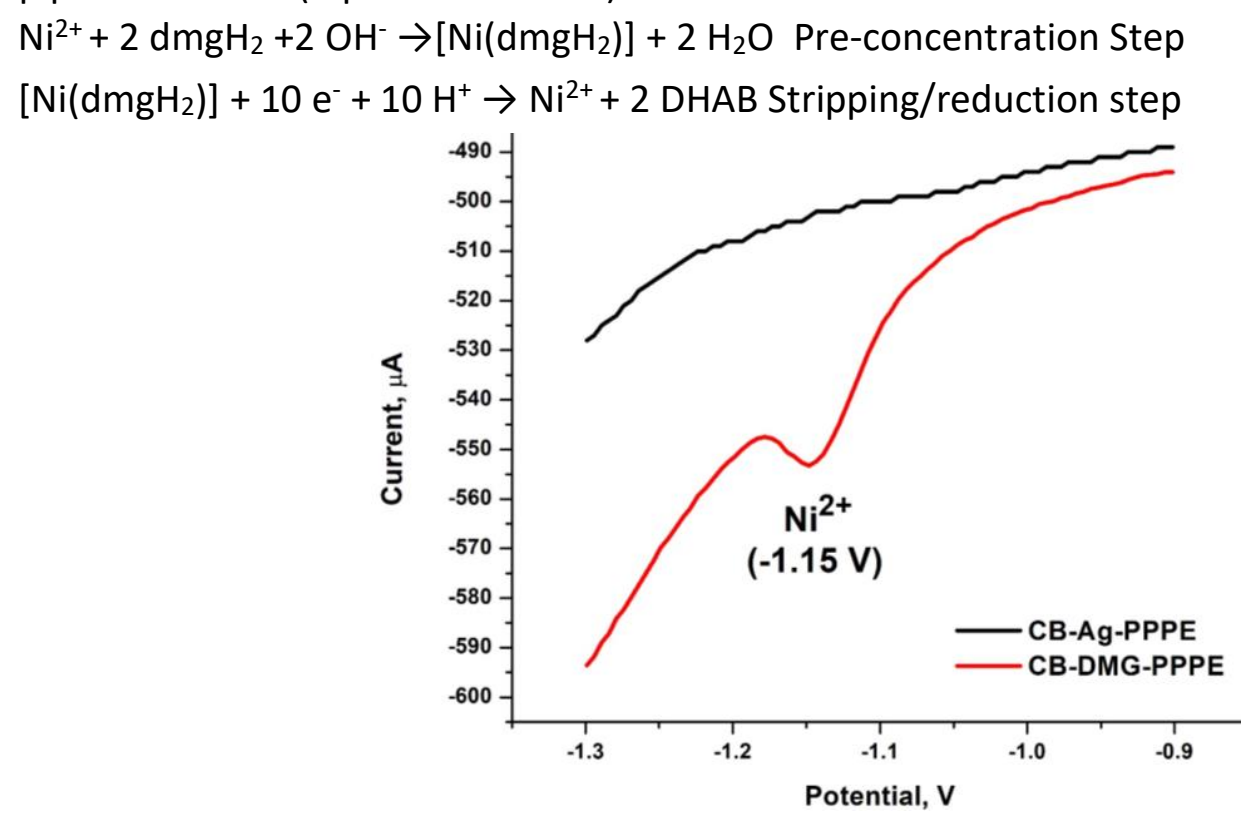

Figure 1. SW-AdCSV of $300 \mu \mathrm{g} \mathrm{L}^{-1} \mathrm{Ni}^{2+}$, obtained at the (a) CB-Ag-PPPE and (b) CB-DMG-Ag-PPPE. Supporting electrolyte (0.1 $\mathrm{NH}_{3} / \mathrm{NH}_{4} \mathrm{Cl}$ Buffer, $\mathrm{pH}$ 9.4), deposition time (90 s), deposition potential (- $\left.0.7 \mathrm{~V}\right)$, rotation speed

(1000 rpm), frequency $(5 \mathrm{~Hz})$, amplitude (0.1 V)

\section{Influence of chelating agent concentration in CB-DMG Ink}

The detection of $\mathrm{Ni}^{2+}$ is highly dependent on the formation of the $\left[\mathrm{Ni}\left(\mathrm{dmgH}_{2}\right)\right]$ and its subsequent adsorption onto the working electrode surface. A sensitive technique was established by immobilizing the chelating agent at the electrode surface, simplifying the stripping voltammetric mechanism. Here, its application at printed paper electrodes was achieved. Optimization of the dimethylglyoxime loading within the prepared carbon black ink (CB:DMG) is illustrated in Figure 2 below. The CB:DMG ratios were varied between 1:0, 1:4, 1:2, and 1:1, and its effect on the stripping voltammetric peak currents were investigated towards $300 \mu \mathrm{g} \mathrm{L}^{-1} \mathrm{Ni}^{2+}$ detection by AdCSV. The absence of a chelating agent (CB:DMG, 1:0) prevents adequate pre-concentration of $\mathrm{Ni}^{2+}$ at the electrode surface and no cathodic stripping peak is observed, as previously stated.

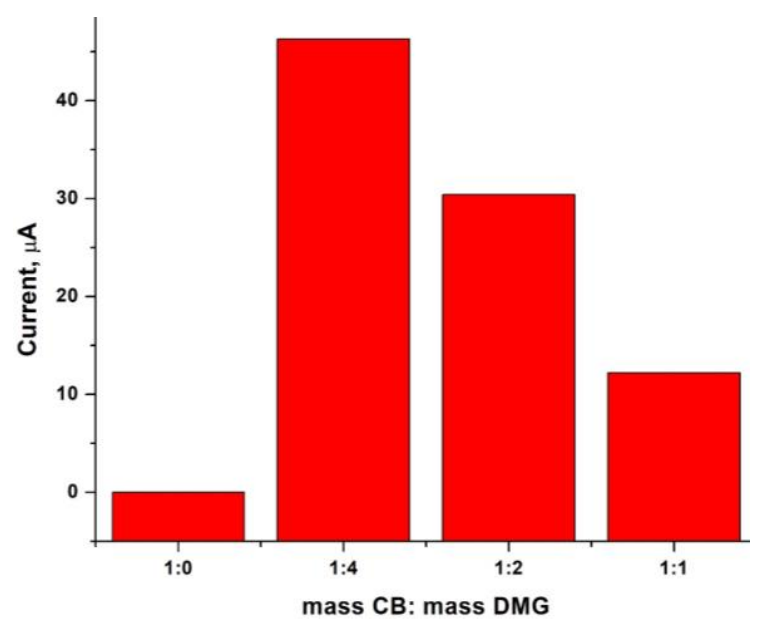

Figure 2. Influence of DMG loading within carbon black inks on the stripping peak current of $300 \mu \mathrm{g} \mathrm{L}^{-1} \mathrm{Ni}^{2+}$.

The addition of a DMG chelating agent at the working electrode facilitates the adsorption of metal cations onto the electrode surface and the subsequent formation of metallo-chelate 
complexes. $\mathrm{Ni}^{2+}$, present in larger concentrations can now be reduced and a stripping peak current achieved. The inclusion of more non-conductive DMG inhibits electron flow and a decrease in the measured peak current is seen. A 1:4 weight ratio of CB:DMG yielded the optimum stripping peak currents and was therefore selected for all further experiments.

\section{Morphological characterization of CB-DMG-Ag-PPPE}

The morphological characterization of the prepared electrodes was studied by scanning electron microscopy. Figure 3 shows the high-resolution electron microscope (HRSEM) images of (a) unmodified inkjet printed AgNP electrode, (b) carbon black modified Ag-electrode and (c) dimethylglyoxime, carbon black Ag-electrode. The HRSEM image of the unmodified AgNP electrode shows a uniform film of spherical Ag nanoparticles deposited on the photographic paper substrate. An even coating with no distinct defects in the printing process is observed. Figure $3 \mathrm{~B}$ demonstrates 'bushy' aggregates of carbon black particles deposited on the silver WE surface shown by spherical particles. Carbon black nanoparticles with an average particle size of $\sim 80 \mathrm{~nm}$ are observed. Adequate surface coverage of the printed paper electrode surface is observed with a somewhat uniform distribution. Upon inclusion of dimethylglyoxime chelating agent in a 1:4 ratio, crystalline deposits can be seen within the carbon black film with an uneven surface distribution as indicated in Figure $3 \mathrm{C}$ and confirm the formation of the CB-DMG composited electrode.

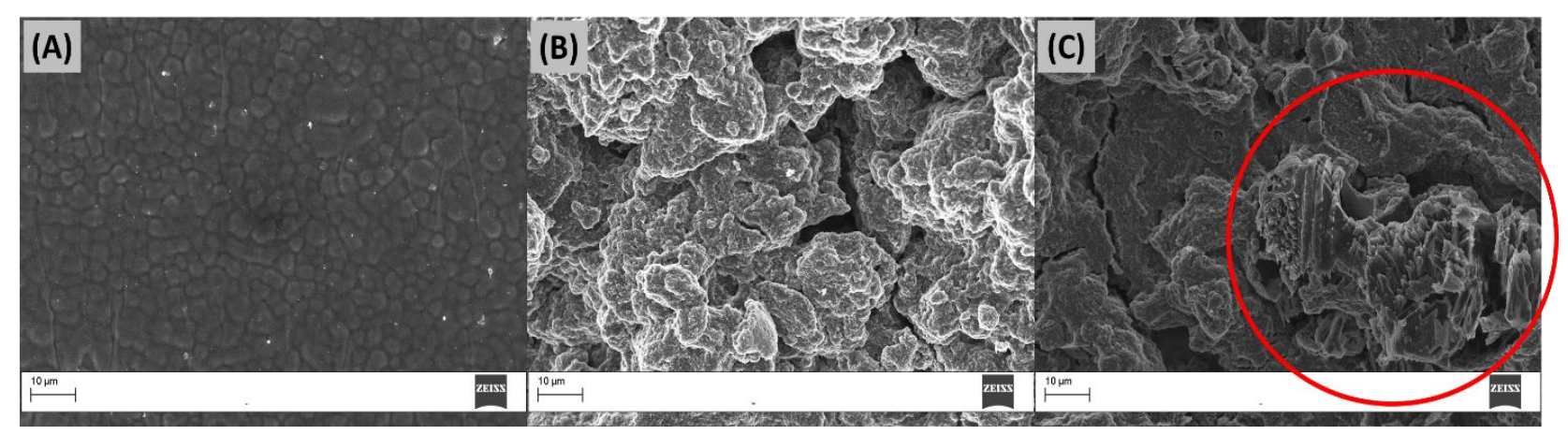

Figure 3: High resolution scanning electron microscope images of (a) inkjet printed AgNPs, (b) CB-AgNP and (c) DMG-CB-AgNP working electrodes on photographic paper at $1 \mathrm{kX}$ magnification.

\section{CB-DMG-Ag-PPPE instrumental parameter optimization}

The square wave instrumental parameters affecting the analytical response of the CB-DMG-AgPPPE; namely deposition potential, deposition time, frequency, and amplitude were optimized and illustrated in Figure 4.

The influence of deposition potential on the stripping response of $\mathrm{Ni}^{2+}$ at the CB-DMG-Ag-PPPE was interrogated in the potential range between 0.0 and $-1.0 \mathrm{~V}$ (Figure 4A). Variations in the accumulation potential towards the established reduction potential of $\mathrm{Ni}^{2+}$ into $\mathrm{Ni}^{0}(0 \mathrm{~V}$ to -0.8$)$, showed a gradual decrease in recorded peak currents achieved from $\mathrm{Ni}^{2+}$ detection. Reduction of the metal cations present in solution converts metal cations to their neutral state lowering the overall concentrations of cations available for reduction in the cathodic sweep. A further move to $-1.0 \mathrm{~V}$, sharply decreases the stripping peak currents. $E_{\text {acc }}$ of $-0.75 \mathrm{~V}$ was selected.

The effect of accumulation time on the $\mathrm{Ni}^{2+}$ stripping response was studied between 30 and $300 \mathrm{~s}$. Figure 4B, shows a rapid increase in the $\mathrm{Ni}^{2+}$ peak current with increasing accumulation time between 0 and $180 \mathrm{~s}$ confirming the increase in adsorption of the $\mathrm{Ni}^{2+}$ on the CB-DMG-Ag-PPPE surface. Saturation of the electrode surface takes place at accumulation times greater than $180 \mathrm{~s}$ 
and results in a gradual stabilization in stripping peak current. A deposition time of $120 \mathrm{~s}$ was selected for all analyses.

Figure 4C shows the dependence of peak currents on the square wave frequency over the 0 to $30 \mathrm{~Hz}$ range. Maximum stripping voltammetric peak currents are achieved at low-frequency values indicating longer analysis times are required to improve the resolution and sensitivity of the paper-based sensors. A steady decline in reduction peak currents between 5 and $30 \mathrm{~Hz}$ can be seen due to slower electron transfer processes through the DMG film. A frequency of $5 \mathrm{~Hz}$ was selected for the square-wave waveform.

The influence of amplitude on the stripping peak current of $\mathrm{Ni}^{2+}$ was studied between 0 and 20 $\mathrm{mV}$ and shown in Figure 4D. A steady increase in recorded stripping cathodic peak currents is observed.
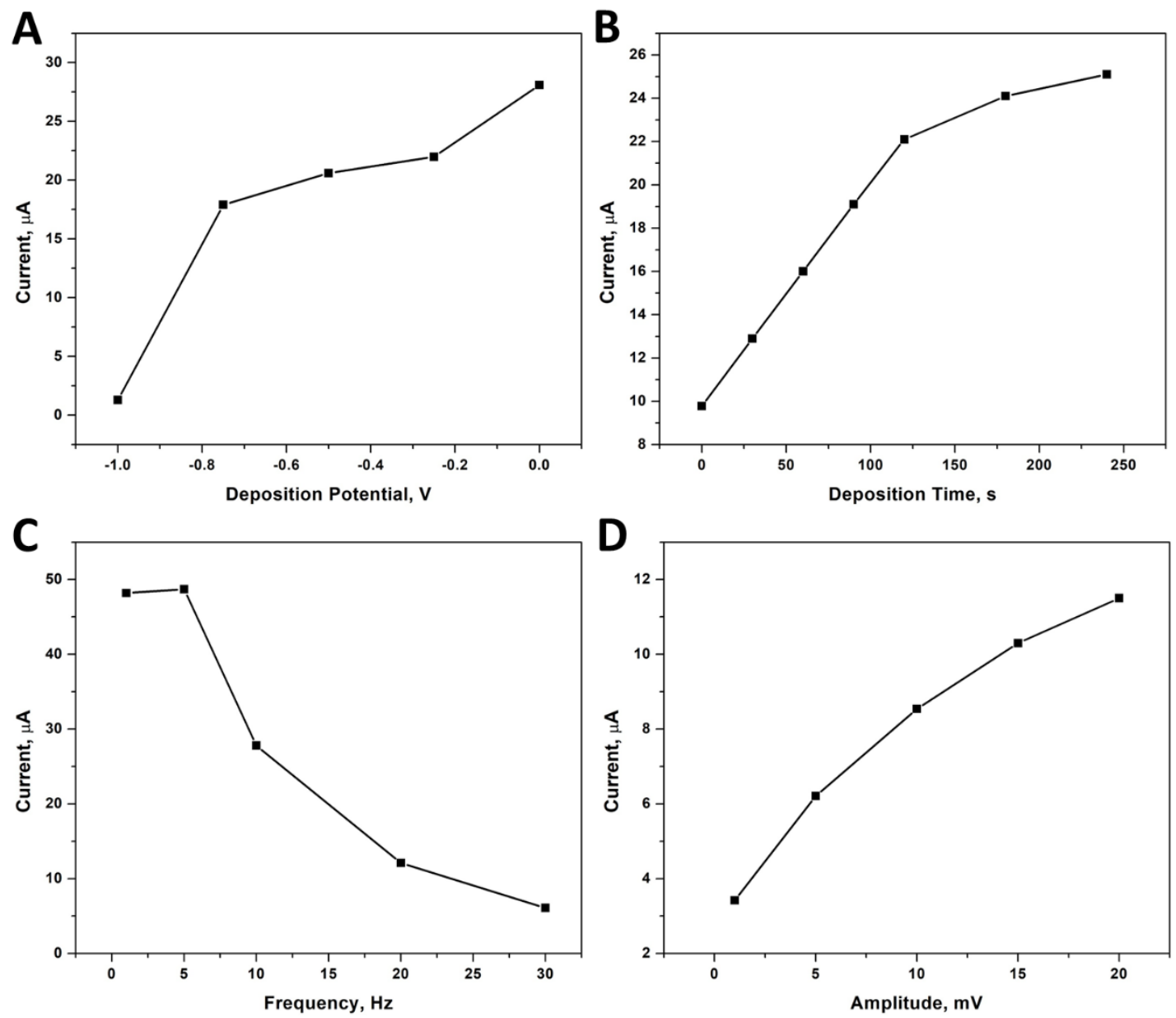

Figure 4. The influence of $(a)$ accumulation potential $\left(E_{a c c}\right)$, (b) accumulation time $\left(t_{a c c}\right)$, (c) frequency, and

(d) amplitude on $\mathrm{Ni}^{2+}$ peak currents at CB-DMG-Ag-PPPE. Sample composition: $300 \mu \mathrm{g} \mathrm{L^{-1 }} \mathrm{Ni}$, $0.1 \mathrm{M} \mathrm{NH}_{3} / \mathrm{NH}_{4} \mathrm{Cl}$ buffer

\section{Quantitative analytical performance of the CB-DMG-Ag-PPPE}

The favorable adsorptive stripping voltammetric performance of the CB-DMG-Ag-PPPE is demonstrated in Figure 5. Square-wave voltammograms and the calculated calibration plot recorded over $50-500 \mu \mathrm{g} \mathrm{L}^{-1} \mathrm{Ni}^{2+}$ ions, at optimum conditions were performed in deaerated samples. The voltammograms were recorded between -0.9 and $-1.3 \mathrm{~V}$. Voltammograms show a single, broad, reversible cathodic stripping peak at $\sim-1.18 \mathrm{~V}$. Peak currents, credited to the reduction of $\mathrm{Ni}^{2+}$ cations from the $\left[\mathrm{Ni}(\mathrm{dmgH})_{2}\right]$ complex increase with increasing $\mathrm{Ni}^{2+}$ concentration. Positive peak potential shifts are indicated at higher metal ion concentrations. The amount of energy to convert 
the cation into its neutral state is therefore decreased. Figure 5 , inset represents the noted calibration plot obtained from the corresponding voltammograms. A constant, linear increase in peak currents is observed between 0 and $350 \mu \mathrm{L} \mathrm{L}^{-1}\left[\mathrm{Ni}(\mathrm{dmgH})_{2}\right]$ concentration. At $\mathrm{Ni}^{2+}$ concentrations greater than $350 \mu \mathrm{g} \mathrm{L}^{-1}$ saturation of the electrode surface with adsorbed metalcomplex is experienced and a deviation from linear concentration is observed. A plateau is evident in the calibration curve. A dynamic linear range between 50 and $350 \mu \mathrm{g} \mathrm{L}-1$ [Ni(dmgH) 2 concentration is established with a correlation coefficient of 0.989 indicating good linearity in the recorded region at an accumulation time of $90 \mathrm{~s}$. Table 1 is a summary of the analytical parameters obtained from the calibration curve.

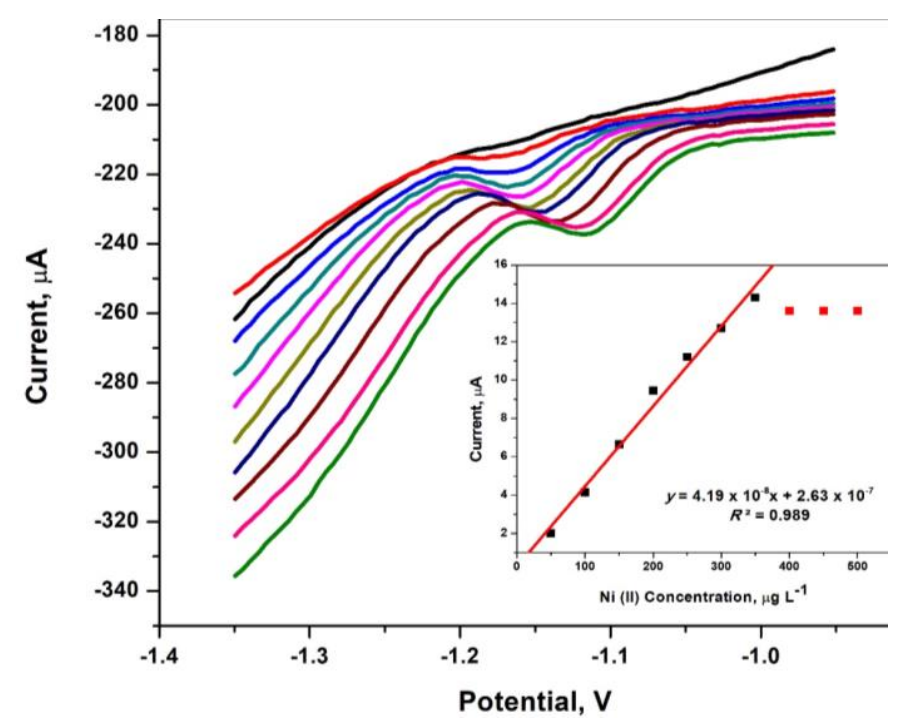

Figure 5. SW-AdCSVs and corresponding calibration plot of individual analysis of $\mathrm{Ni}^{2+}$ obtained at CB-DMG-CCAg-PPE over a $50-500 \mu g L^{-1}$ range. Supporting electrolyte $0.1 \mathrm{NH}_{3} / \mathrm{NH}_{4} \mathrm{Cl}$ Buffer, $\mathrm{pH} 9.4$, deposition time $90 \mathrm{~s}$, deposition potential $-0.7 \mathrm{~V}$, rotation speed $1000 \mathrm{rpm}$, frequency $5 \mathrm{~Hz}$, amplitude $0.01 \mathrm{~V}$

Table 1. A summary of recorded analytical data for the CB-DMG-Ag-PPE over the $50-500 \mu g L^{-1}$ range

\begin{tabular}{cc}
\hline Analytical Parameter & Analysis of $\mathrm{Ni}^{2+}$ \\
\hline Sensitivity, $\mu \mathrm{A} \mathrm{L \mu \textrm {g } ^ { - 1 }}$ & $4.1910^{-8}$ \\
\hline Correlation coefficient & 0.989 \\
\hline Detection limit $\pm \mathrm{SD}, \mu \mathrm{g} \mathrm{L}$ & $48.01 \pm 12.24$ \\
\hline Limit of quantification $\pm \mathrm{SD}, \mu \mathrm{L} \mathrm{L}^{-1}$ & $144.03 \pm 51.92$
\end{tabular}

Analysis of tap water samples at the CB-DMG-Ag-PPPE

The carbon black, dimethylglyoxime paper-based sensor (CB-DMG-Ag-PPPE) was applied to the quantitative analysis of $\mathrm{Ni}^{2+}$ ions in tap water samples collected in our laboratory. Quantitative analysis of tap water was performed using a simple standard addition technique whereby successive additions of known sample concentrations were added to the sample under analysis to determine its concentration by extrapolation methods. The recorded voltammogram and standard addition calibration curve are shown in Figure 6. 

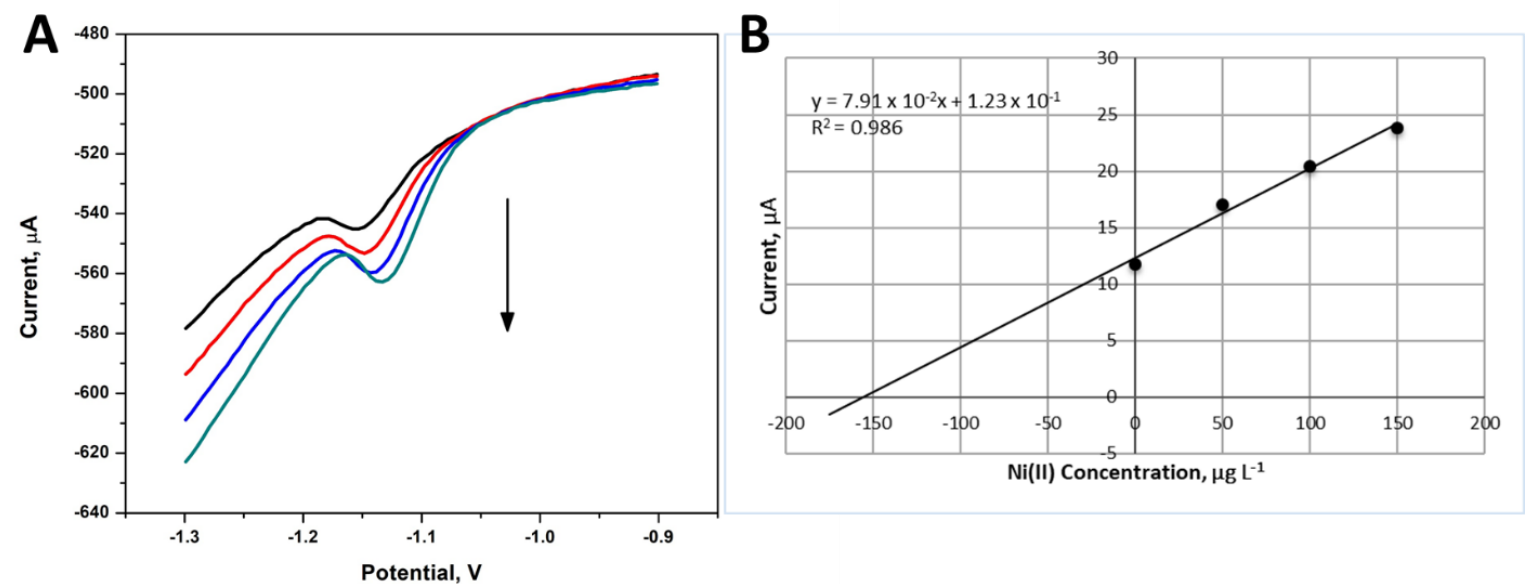

Figure 6. Analysis of tap water ( $\mathrm{pH}$ 9.4) spiked with $150 \mu \mathrm{gL}^{-1}$ of the metal ion in the presence of $2 \mathrm{mM} \mathrm{DMG}$ and $10 \mathrm{mg} \mathrm{L}^{-1} \mathrm{Hg}^{3+}$. (a) SW-AdSV and (b) Calibration plot. Supporting electrolyte: $0.1 \mathrm{M} \mathrm{NH}_{3} / \mathrm{NH}_{4} \mathrm{Cl}$ buffer

(pH 9.4). SWV instrumental parameters: $\mathrm{E}_{a c c}=-0.7 \mathrm{~V}, \mathrm{t}_{\text {acc }}=120 \mathrm{~s}, \mathrm{f}=5 \mathrm{~Hz}$ and amplitude $=10 \mathrm{mV}$.

A linear increase in peak current was observed with increasing "spike" concentration with good regression of 0.986 . The extrapolated $\mathrm{x}$-intercept was used to determine the concentration of $\mathrm{Ni}^{2+}$ cations in the unknown sample. A summary of the reported values for $\mathrm{Ni}^{2+}$ concentrations found in both the spiked and un-spiked samples are shown in Table 2, below. The samples were analysed before (original) and after (found) known concentrations (added) of $\mathrm{Ni}^{2+}$ were added. It was found that the $\mathrm{Ni}^{2+}$ ion concentration in tap water samples could not be determined as it was below the sensor limits of detection or was not present in the sample at all. Spiked samples allowed for accurate recovery studies in the new sample matrix when studied within the linear dynamic range found previously. Good recovery percentages were determined for $\mathrm{Ni}^{2+}$ detection in both test (buffer) and real tap water samples respectively with an error below $5 \%$.

Table 2. Recorded recovery percentages in both test and water samples

\begin{tabular}{|c|c|c|c|c|}
\hline \multirow{2}{*}{$\mathrm{Ni}^{2+}$ sample } & \multicolumn{3}{|c|}{$c_{\mathrm{Ni}} / \mu \mathrm{g} \mathrm{L}^{-1}$} & \multirow{2}{*}{ Recovery, \% } \\
\hline & Original $^{1}$ & Added $^{2}$ & Found $^{3}$ & \\
\hline Test sample & $\mathrm{N} / \mathrm{D}$ & 150 & 148.15 & $98.77 \pm 7.41$ \\
\hline Real water sample & $N / D$ & 150 & 155.49 & $103.66 \pm 5.34$ \\
\hline
\end{tabular}

A summary of the work performed at DMG modified electrodes is shown in Table 3, below. Limits of detection ranging from 0.5 to $48 \mu \mathrm{g} \mathrm{L-1}$ were observed. Solid electrodes like glassy carbon and screen-printed electrodes provided the lowest limits of detection owing to the high conductivity of the solid substrates even at shorter analysis times. DMG modified carbon paste electrodes were also studied in select works. Previous work done in paper-based sensors by our research group is also shown. Paper-based electrochemical cells used in conjunction with SPCEs demonstrated slightly lower sensitivity due to the low sample volumes required for analysis, limiting the number of available ions for detection. As expected, the two works performed in paper-based sensors showed low sensitivity owing to the lack of electron transport in the cellulose matrix. The ERGO-AuNP-CC-Ag-PPPE in conjunction showed improved LOD because of the mercury film. 
Table 3. A summary of recent work performed at DMG modified electrodes

\begin{tabular}{|c|c|c|c|c|c|c|}
\hline Metal ions & Substrate & Technique & $\begin{array}{c}\text { Accumulation } \\
\text { time, } s\end{array}$ & $\begin{array}{l}\text { Dynamic linear } \\
\text { range, } \mu g \mathrm{~L}^{-1}\end{array}$ & $\begin{array}{l}\text { Detection } \\
\text { limit, } \mu g \mathrm{~L}^{-1}\end{array}$ & Ref. \\
\hline $\mathrm{Ni}^{2+}$ & DMG-CPE & DPAdSV & 120 & $80-600$ & 27 & {$[2]$} \\
\hline $\mathrm{Ni}^{2+}$ & DMG-N-SPE & DPAdSV & 120 & $60-500$ & 30 & [3] \\
\hline $\mathrm{Ni}^{2+}$ with $\mathrm{Co}^{2+} \& \mathrm{Zn}^{2+}$ & NGr-DMG-GCE & SWAdCSV & 120 & $2-20$ & 1.5 & [4] \\
\hline $\mathrm{Ni}^{2+}$ & DMG-Hg- $\mu$ PPEC & SWAdCSV & 90 & $15-90$ & 6.27 & {$[5]$} \\
\hline $\mathrm{Ni}^{2+}$ & ERGO-AuNP-CC-Ag-PPPE & SWAdCSV & 120 & $50-500$ & 32.19 & {$[6]$} \\
\hline $\mathrm{Ni}^{2}$ & DMG-SPCE & DPAdSV & 120 & $1.7-150$ & 0.5 & [7] \\
\hline $\mathrm{Ni}^{2}$ & DMG-SPCE & SWAdSV & 60 & $7.6-200$ & 2.3 & [8] \\
\hline $\mathrm{Ni}^{2}$ & DMG-CPE & DPAdSV & 120 & $50-340$ & 27 & [9] \\
\hline $\mathrm{Ni}^{2+}$ & CB-DMG-Ag-PPPE & SWAdCSV & 120 & $50-350$ & 48.01 & This work \\
\hline
\end{tabular}

\section{Conclusion}

This study describes a simple inkjet printing process to produce patterned three-electrode systems based on silver nanoparticles (AgNPs) deposited on commercial photographic paper without the need for stencils or templates. The use of nanoparticles in the electrode fabrication provided highly conductive and reproducible electrodes with uniform morphology. The fabricated Ag-PPE showed good conductivity in the low ohm range. Further, modification of the Ag-PPE with a nafion carbon black dimethylglyoxime film demonstrated improved sensitivity and provided an accurate and simple quantitative analytical approach towards the detection of $\mathrm{Ni}^{2+}$ in drinking water samples by adsorptive cathodic stripping voltammetry (AdCSV). This was the first reported work on a carbon black dimethylglyoxime composite and the first use of carbon black as ink in paper-based sensing applications. The sensors provided good sensitivities and low limits of detection at short analysis times compared to similar studies on paper-based sensing and is only the second study showcasing paper-based devices in adsorptive stripping voltammetric applications. The work demonstrated a further approach to metal analysis at paper-based electrodes in the absence of commonly used metallic films and showcased comparable results to these. Accurate detection in the 98-103\% range was observed for test and real water samples. Further work is required to improve the low sensitivity of the paper-based substrates and investigate other nanostructured materials and fabrication processes for paper-based sensor development.

Accknowledgement: The work has been supported in part by the National Research Foundation (NRF) of South Africa.

\section{References}

[1] A. Ahmed, Journal of Bacteriology and Mycology 6(3) (2018) 179-181. https://doi.org/ 10.15406/jbmoa.2018.06.00199

[2] E. S. Forzani, H. Zhang, W. Chen, N. Tao, Environmental Science and Technology 39(5) (2005) 1257-1262. https://doi.org/10.1021/es049234z

[3] L. Eddaif, A. Shaban, J. Telegdi, International Journal of Environmental Analytical Chemistry 99(9) (2019) 824-853. https://doi.org/10.1080/03067319.2019.1616708

[4] F. Ma, D. Jagner, L. Renman, Analytical Chemistry, 69(9) (1997) 1782-1784. https://doi.org/ 10.1021/ac961023s

[5] M. Rosal, X. Cetó, N. Serrano, C. Ariño, M. Esteban, J. M. Díaz-Cruz, Journal of Electroanalytical Chemistry 839 (2019) 83-89. https://doi.org/10.1016/i.jelechem. $\underline{2019.03 .025}$ 
[6] J. Zen, N. Chi, F. Hsu, M. Chung, Analyst 120 (1995) 0-4. https://doi.org/10.1039/AN9952 $\underline{000511}$

[7] K. Pokpas, N. Jahed, E. McDonald, P. Bezuidenhout, S. Smith, K. Land, E. Iwuoha, Electroanalysis 32(12) (2020) 3017-3031. https://doi.org/10.1002/elan.202060379

[8] K. Pokpas, N. Jahed, P. G. Baker, E. I. Iwuoha, Sensors 17(8) (2017) 1711. https://doi.org/ 10.3390/S17081711

[9] B. H. Nguyen, B. T. Nguyen, H. V. Vu, C. V. Nguyen, D. T. Nguyen, L. T. Nguyen, T. T. Vu, L. D. Tran, Current Applied Physics 16(2) (2016) 135-140. https://doi.org/10.1016/i.cap.2015. $\underline{11.004}$

[10] M. Pumera, Electrochemistry Communications 36 (2013) 14-18. https://doi.org/10.1016/ j.elecom.2013.08.028

[11] T. Vural, F. Kuralay, C. Bayram, S. Abaci, E. B. Denkbas, Applied Surface Science 257(2) (2010) 622-627. https://doi.org/10.1016/i.apsusc.2010.07.048

[12] I. Taurino, S. Carrara, M. Giorcelli, A. Tagliaferro, G. de Micheli, Surface Science 606(3) (2012) 156-160. https://doi.org/10.1016/i.susc.2011.09.001

[13] L. Li, D. Liu, A. Shi, T. You, Sensors and Actuators B 255 (2018) 1762-1770. https://doi.org/10.1016/i.snb.2017.08.190

[14] E. Punrat, C. Maksuk, S. Chuanuwatanakul, W. Wonsawat, O. Chailapakul, Talanta 150 (2016) 198-205. https://doi.org/10.1016/i.talanta.2015.12.016

[15] R. N. Goyal, V. K. Gupta, N. Bachheti, Analytica Chimica Acta 597(1) (2007) 82-89. https://doi.org/10.1016/j.aca.2007.06.017

[16] A. Wong, A. M. Santos, O. Fatibello-Filho, Sensors and Actuators B 255 (2018) 2264-2273. https://doi.org/10.1016/i.snb.2017.09.020

[17] J. Smajdor, R. Piech, M. Ławrywianiec, B. Paczosa-Bator, Analytical Biochemistry 544 (2018) 7-12. https://doi.org/10.1016/i.ab.2017.12.025

[18] J. Hu, Z. Zhang, Nanomaterials, 10(10) (2020) 1-14. https://doi.org/10.3390/nano10102020

[19] T. A. Silva, F. C. Moraes, B. C. Janegitz, O. Fatibello-Filho, D. Ganta, Journal of Nanomaterials 2017 (2017) 1-14. https://doi.org/10.1155/2017/4571614

[20] F. Arduini, S. Cinti, V. Mazzaracchio, V. Scognamiglio, A. Amine, D. Moscone, Biosensors and Bioelectronics 156 (2020). https://doi.org/10.1016/i.bios.2020.112033

[21] K. Y. Hwa, T. S. K. Sharma, P. Karuppaiah, New Journal of Chemistry 43(30) (2019) 1207812086. https://doi.org/10.1039/c9nj02531f

[22] M. Cirrincione, B. Zanfrognini, L. Pigani, M. Protti, L. Mercolini, C. Zanardi, Analyst 146(2) (2021) 612-619. https://doi.org/10.1039/d0an01932a

[23] L. P. Silva, T. A. Silva, F. C. Moraes, O. Fatibello-Filho, Journal of Solid State Electrochemistry 24(8) (2020) 1827-1834. https://doi.org/10.1007/s10008-020-04541-1

[24] M. Łysoń, A. Górska, B. Paczosa-Bator, R. Piech, Electrocatalysis 12(6) (2021) 641-649. https://doi.org/10.1007/s12678-021-00676-5

[25] J. V. Maciel, G. D. da Silveira, A. M. M. Durigon, O. Fatibello-Filho, D. Dias, Talanta 236(1) (2022) 122881. https://doi.org/10.1016/i.talanta.2021.122881

[26] R. Xie, L. Zhou, C. Lan, F. Fan, R. Xie, H. Tan, T. Xie, L. Zhao, Royal Society Open Science 5(7) (2018) 1-10. https://doi.org/10.1098/rsos.180282

[27] A. Gorska, B. Paczosa-Bator, R. Piech, Sensors 21(1) (2021) 60. https://doi.org/10.3390/ $\underline{\mathrm{s} 21010060}$

[28] I. Bargiel, J. Smajdor, A. Gorska, B. Paczosa-bator, R. Piech, Materials 14(24) (2021) 7582. https://doi.org/10.3390/ma14247582

[29] P. Lisowski, P. K. Zarzycki, Camera Separatoria 4(2) (2012) 143-149. 
[30] J.-W. Tortorich, Ryan P. Song, E. Choi, 224 ${ }^{\text {th }}$ ECS Meeting, 224th ECS Meeting Abstracts 2013, San Francisco, California, USA, 2013, 2765. http://toc.proceedings.com/22193 webtoc.pdf

[31] R. Tortorich, H. Shamkhalichenar, J.-W. Choi, Applied Sciences 8(2) (2018) 288-304. https://doi.org/10.3390/app8020288

[32] E. Song, R. P. Tortorich, T. H. da Costa, J. W. Choi, Microelectronic Engineering 145 (2015) 143-148. https://doi.org/10.1016/i.mee.2015.04.004

[33] M. Mass, L. S. Veiga, O. Garate, G. Longinotti, A. Moya, E. Ramon, R. Villa, G. Ybarra, G. Gabriel, Nanomaterials 11(7) (2021) 1645. https://doi.org/10.3390/nano11071645

[34] P. Rewatkar, P. K. Enaganti, M. Rishi, S. Mukhopadhyay, S. Goel, International Journal of Hydrogen Energy 46(71) (2021) 35408-35419. https://doi.org/10.1016/j.ijhydene.2021. $\underline{08.102}$

[35] T. Kant, K. Shrivas, K. Tapadia, R. Devi, V. Ganescan, M. K. Deb, New Journal of Chemistry 45 (2021) 8297-8305. https://doi.org/10.1039/D1NJ00771H

[36] E. Kuusisto, J. J. Heikkinen, P. Jarvinen, T. Sikanen, S. Franssila, Sensors and Actuators B 336(1) (2021) 129729. https://doi.org/10.1016/i.snb.2021.129727

[37] P. B. Deroco, D. W. Junior, L. T. Kubota, Chemosensors 9(4) (2021) 61. https://doi.org/10.3390/chemosensors9040061

[38] S. Dudala, S. Srikanth, S. K. Dubey, A. Javed, S. Goel, Micromachines 12(9) (2021) 1-13. https://doi.org/10.3390/mi12091037

[39] B. Li, X. Liang, G. Li, F. Shao, T. Xia, S. Xu, N. Hu, Y. Su, Z. Yang, Y. Zhang, ACS Applied Materials and Interfaces 12(35) (2020) 39444-39454. https://doi.org/10.1021/acsami.0c11788

[40] I. J. Fernandes, A. F. Aroche, A. Schuck, P. Lamberty, C. R. Peter, W. Hasenkamp, T. L. A. C. Rocha, Scientific Reports 10(1) (2020) 8878. https://doi.org/10.1038/s41598-020-65698-3

[41] S. Lai, Y. Vlamdis, N. Mishra, P. Cosseddu, V. Miseikis, P. C. Ricci, V. Voliani, C. Coletti, A. Bonfiglio, Advanced Materials Technologies 6(12) (2021) 2100481. https://doi.org/ 10.1002/admt.202100481

[42] T. Pandhi, C. Cornwell, K. Fujimoto, P. Barnes, J. Cox, H. Xiong, P. H. Davis, H. Subbaraman, J. E. Koehne, D. Estrada, RSC Advances 10(63) (2020) 38205-38219. https://doi.org/10.1039/dOra04786d

[43] E. Bihar, D. Corzo, T. C. Hidalgo, D. Rosas-Villalva, K. N. Salama, S. Inal, D. Baran, Advanced Materials Technologies, 5(8) (2020) 2000226. https://doi.org/10.1002/admt.202000226

[44] K. Pokpas, N. Jahed, E. Iwuoha, Electrocatalysis 10(4) (2019) 352-364. https://doi.org/ 10.1007/s12678-019-00516-7

(C)2022 by the authors; licensee IAPC, Zagreb, Croatia. This article is an open-access article distributed under the terms and conditions of the Creative Commons Attribution license (https://creativecommons.org/licenses/by/4.0/) 